\title{
Editorial
}

\section{Delivering race equality in mental health services}

\author{
Annie Lau
}

\begin{abstract}
Delivering race equality' is a 5-year action plan for tackling race inequalities in mental healthcare in England and Wales, based on the main themes of improved services, better community engagement and better information. The perception is that clinical teams have not been sufficiently engaged with the plan and progress is slow. This article shares insights from the author's work across government departments over the past 2 years and explores the potential for linking up different initiatives across the patient care pathway in support of the plan's delivery. A summary of conclusions from a pilot survey of consultant psychiatrists, commissioned by the Department of Health in June 2007, addresses the main controversial areas in the action plan, with suggestions for improvement. Areas for clinical engagement are identified that exploit new funding, investment and policy initiatives. Examples of good practice are offered.
\end{abstract}

In 2006, I was the Medical Advisor in Mental Health in the National Specialist Services Commissioning Advisory Group (NSCAG), Department of Health. I was also invited by Kamlesh Patel, National Strategic Lead, to work across government departments to support the Department of Health's Delivering Race Equality agenda, working mainly with the Home Office and the Department of Education and Skills. The work on Delivering Race Equality is ongoing. This article arose from insights and information gained during this time.

The main goals of the Delivering Race Equality in Mental Health Care Action Plan ${ }^{+}$for England and Wales (Department of Health, 2005) are more appropriate and responsive services, community engagement and better information. The plan sets out 12 characteristics of a reformed service which should be in place by 2010 .

A key outcome measure for the programme is route of admission to hospital. The results of the 2005 and 2006 Count Me In census in England and Wales

${ }^{+}$An outline of Delivering Race Equality appears in McKenzie, K. (2008) Improving mental healthcare for ethnic minorities. Advances in Psychiatric Treatment, 14, 285-291. Ed.
(Healthcare Commission, 2005, 2007), show Black (African-Caribbean and other African) and 'White/ Black Mixed' service users to be three to four times more likely to enter the in-patient care pathway through detention under the Mental Health Act 1983. To obtain a more comprehensive picture of the care pathway of Black and minority ethnic service users, the Department of Health recognises the need to monitor their experience using community, primary care and offender population surveys.

\section{Case for clinical engagement}

How can psychiatrists and their teams most usefully engage with this agenda? There has been much heated debate, most recently in the Psychiatric Bulletin (McKenzie \& Bhui, 2007; Singh, 2007), on whether psychiatric services are institutionally racist, and where the fault lies with regard to poor access to and experience of mental health services by Black and minority ethnic service users and families. 'Whole system' changes are needed at a number of different levels and across organisations. As clinical leaders we need to reach out and engage with others prepared to make those changes. We

Annie Lau is a child and adolescent psychiatrist with North East London Mental Health NHS Trust (Goodmayes Hospital, Ilford, Essex IG3 8YB, UK. Email: annie.lau@djpconsulting.co.uk). She has been active in cross-cultural psychiatry for the past 30 years, with pioneering work in transcultural family therapy in the UK. In recent years she has concentrated on training clinical teams and trust boards in race and cultural competencies. She was Medical Director, North East London Mental Health Trust from 2001 to 2005 , and Medical Advisor, National Specialist Services Commissioning Advisory Group, Department of Health in 2006. She is currently on the Public Policy Committee at the World Psychiatric Association and the Workforce Symposium. 


\section{Box 1 London initiatives to change attitudes}

- Tower Hamlets Primary Care Trust in east London has set up a series of educational events for general practitioners to promote cultural competency and improve access to mental health services in the Bangladeshi community.

- Rabishikha, a cultural organisation in north London that promotes the work of Rabindranath Tagore, encourages awareness of mental health issues through dance, drama and music. Their dance production Maya (presented at the Bloomsbury Theatre in 2003-2004) carried an anti-stigma message and was part of the Royal College of Psychiatrists' Changing Minds campaign.

need to harness the energies of new policies and invest in new services. We need to challenge our teams to think and act differently (Box 1) and work with our partners in health and social care.

\section{Improving access}

Tackling inequalities is a focus of recent health policy and of Lord Darzi's (2007) report on the future of the National Health Service (NHS). It is also a key objective of primary care trusts (PCTs). Tackling inequalities translates to access across the entire patient care pathway (primary care, secondary services in mental health trusts, specialist tier four services). It also involves reducing stigma and fear of services in the community, as these stand in the way of access. Art, poetry, music, drama and dance can all be used effectively to normalise mental distress, as part of the universal human journey (Box 1).

I believe that the move towards better integration of primary and secondary care in enabling access, as in the polyclinics proposed by Lord Darzi (2007), may offer new opportunities for better sharing of knowledge and skills and better communication across organisational interfaces in healthcare. These new centres may be perceived as less stigmatising by Black and minority ethnic communities and, as such, more accessible.

\section{Informed PCT commissioning of services}

The Department of Health's Care Quality Commission will include commissioning standards in its regulatory portfolio and rate PCT commissioning skills. Clinicians can work with PCT commissioners so that appropriate services are established, with recognition of the needs of Black and minority ethnic service users throughout the health and social care system. The growing consensus is that 'world-class commissioning' (Department of Health, 2007) will mean input from a range of providers, including the voluntary sector. What is important is that service input is integrated and coherent across the entire care pathway, and that it manages to secure service user confidence. Secondary services will need to work with the voluntary sector to ensure that the needs of Black and minority ethnic service users are met along the entire care pathway, including social inclusion and recovery. Primary care counselling should focus on quality and outcomes, not just case-load targets and number of contacts.

\section{Early intervention in psychosis}

Implementation of early intervention in psychosis (EIP or early intervention) teams is now mandatory in all mental health trusts in England. Where properly funded and resourced, these teams are not only reducing the duration of untreated psychosis, but are also returning young people to meaningful social roles in the family and community, and getting them back into school, college, training and employment. Early findings (as yet unpublished) from a Londonwide survey of which I am Project Lead suggest good uptake of early intervention services by Black and minority ethnic users, but this needs to be documented by ethnic monitoring.

The Learning and Skills Council (2006) is committed to improving services for people with mental health difficulties by building service capacity, boosting the demand for learning, monitoring quality and raising achievement levels. Over the next 2 years, nine regional networks in England will work to promote and improve access to learning and skills for people with mental health difficulties, including those with intellectual disabilities. Mental health professionals need to take up the opportunity for partnership with further education providers, given the political will that now exists. There is a particular focus on training that can lead to employment. If early intervention services engage effectively and consistently with local further education colleges, the trend noted in recurrent census surveys of adverse care pathways for Black and minority ethnic service users may well be reversed.

\section{Improving access to talking therapies and safe in-patient environments}

Access to talking therapies should be a matter of right for all service users, but shortages of psychotherapists and counsellors are common on mental health units. The government has signalled new investment ( $£ 170$ million; Her Majesty’s Treasury, 
2007) in England and Wales to shorten waiting lists, with PCTs acting as centres of excellence and local demonstration sites ('beacon sites') for the provision of cognitive-behavioural therapy (CBT) (www.mh choice.csip.org.uk/psychological-therapies.html). This should lead to better provision of psychological therapies for Black and minority ethnic groups, but current research shows that adequate access to services does not suffice. For example, the evidence shows low engagement and high drop-out for Black service users diagnosed with schizophrenia who are offered a brief CBT package (Rathod et al, 2005). The reasons for this are currently being evaluated, but all clinicians need to contribute to documenting which therapeutic interventions are most effective in engaging patients from Black and minority ethnic groups. I wonder whether brief (six-session) focused CBT would be sufficient to address the more complex needs of some of these patients. I would suggest that successful treatment also requires connection with the patient's value and meaning systems, including religious belief.

Good practice identified in acute care forums in NHS trusts should be harnessed and cascaded (Box 2). For example, all in-patient nurses should be expected to use therapeutic observations of patients at clinical risk, and also have access to regular supervision.

\section{The pathway to forensic care}

As Medical Advisor in Mental Health in NSCAG in 2006, I had responsibility for the national adolescent forensic mental health services, and liaison work with the Youth Justice Board of the Home Office. I have become increasingly aware that individuals in young offender institutions, prisons and probation services, where Black and minority ethnic groups are overrepresented, still have inadequate access to good mental healthcare. Services exist in 'silos', often with barriers to good communication. These

\section{Box 2 Nurse therapists}

In Enfield, a skilled nurse therapist runs cognitive-behavioural therapy traininggroups for nurses from in-patient units in Chase Farm Hospital. Nurses that have taken up these skills have been empowered to engage much more successfully with patients, including those from Black and minority ethnic groups, improving their treatment experience and outcomes.

\section{Parry, Barnet Enfield Haringey NHS Trust,} personal communication, 2008

\section{Box 3 Taking a stand against stereotyping}

At a care programme approach (CPA) discharge planning review meeting for a young Black man who had turned 18 and was to leave a forensic secure adolescent unit, the clinician noted that her team wanted to assign a highrisk rating, despite the fact that the man had displayed no aggressive behaviour during his 3-year stay. Hehad also made good educational progress. She argued for a more realistic, and lower, risk rating. She believed that her staff had been unjustifiably intimidated by the man's large build and ethnicity.

organisational barriers, and a lack of appropriate resources to ensure continuity of care plans, make transitions between services, particularly between different age groups, fraught with risks for patients. In interdepartmental meetings, I was informed that senior Home Office staff feel that health and social care services do not provide good aftercare for offenders, regardless of their ethnicity, following discharge from custody. As a result, people get sucked back into old patterns that lead to a return to offending behaviour.

Adult medium secure services find it difficult to offer timely in-patient assessment and treatment of offenders with mental illnesses, as beds are blocked by a lack of step-down high-dependency units in the community to which patients still requiring high levels of supervision and support can be appropriately and safely discharged. Also, the Policy Division of the Youth Justice Board identified a pattern of more punitive sentencing by the judiciary of young Black men, given similar patterns of offences (Bill Kerslake, Head of Policy, Youth Justice Board, personal communication, 2006). In this context, the needs of Black and minority ethnic offenders tend to get lost. Good practice examples are, however, to be found (Box 3).

\section{Involving patients and carers}

Capturing patient experience and feedback about services has to be fundamental in engaging patients, enabling them to exercise choice and involving them in planning for improvement (Box 4). Given the importance of the individual within the family in traditional Black and minority ethnic communities, it is crucial to work with the family in considering the impact of a relative's mental the illness on family functioning. Unfortunately, ethnic and cultural issues are frequently not taken into consideration in the care plan. 


\section{Box 4 Involving patients and carers}

- Patient Voices (www.patientvoices.org.uk) enables patients, carers and clinicians to post their experiences of healthcare on its website. An extensive repertoire of 3-min 'digital stories' includes those from Black and minority ethnic mental health service users. The stories are freely available for use in medical education in the UK and abroad, and for healthcare quality improvement.

- I asked a non-Muslim resident of a national forensic adolescent unit to tell me how the unit was dealing with the death of a Muslim boy. He said that he had found the recent visit of the local imam useful and thoughtprovoking. The imam met with staff and residents, and talked about the meaning of the dead boy's name and helped them to talk about positive features of his life within a context of Islamic values.

\section{Findings from new research}

The AESOP (Aetiology and Ethnicity in Schizophrenia and Other Psychoses) study (Morgan et al, 2006) has made it clear that different Black and minority ethnic groups have different vulnerabilities and needs and unequal access to services. More must be done to understand care pathways and antecedents to health and social care. Specific needs of particular groups, such as British people of Caribbean and African origin (McKenzie, 2007) and young Asian women (Bhugra \& Desai, 2002), have to be considered.

Can we reclaim the territory and do better for Black and minority ethnic service users, as we look forward to 2010?

\section{Declaration of interest}

A.L. is working for the Department of Health in furthering the Delivering Race Equality objectives.

\section{References}

Bhugra, D. \& Desai, M. (2002) Attempted suicide in South Asian women. Advances in Psychiatric Treatment, 8, 408-423.

Darzi, A. (2007) Our NHS, Our Future. NHS Next Stage Review: Interim Report. Department of Health.

Department of Health (2005) Delivering Race Equality in Mental Health Care: An Action Plan for Reform Inside and Outside Services and the Government's Response to the Independent Inquiry into the Death of David Bennett. TSO (The Stationery Office).

Department of Health (2007) World Class Commissioning: Vision. Department of Health.

Healthcare Commission (2005) Count Me In. Results of a National Census of Inpatients in Mental Health Hospitals and Facilities in England and Wales. Commission for Healthcare Audit and Inspection (http:/ / www.healthcarecommission.org.uk/_db/_ documents/04021830.pdf).

Healthcare Commission (2007) Count Me In. Results of the 2006 National Census of Inpatients in Mental Health and Learning Disability Services in England and Wales. Commission for Healthcare Audit and Inspection (http://www.healthcarecommission. org.uk/_db/_documents/Count_Me_In_2006.pdf).

Her Majesty's Treasury (2007) Meeting the Aspirations of the British People: 2007 Pre-Budget Report and Comprehensive Spending Review, Annex D2. TSO (The Stationery Office).

Learning and Skills Council (2006) Improving Services for People with Mental Health Difficulties. LSC (http:/ / readingroom.lsc.gov.uk/ lsc/2006/learningopportunities/promotion/nat-improving servicesforpeoplewithmentalhealthdifficulties-ps-aug2006. pdf).

McKenzie, K. (2007) Being black in Britain is bad for your mental health. The Guardian, 2 April.

McKenzie, K. \& Bhui, K. (2007) Better mental healthcare for minority ethnic groups - moving away form the blame game and putting patients first. Commentary on... Institutional racism and psychiatry. Psychiatric Bulletin, 31, 368-369.

Morgan, C., Dazzan, P., Morgan, K., et al (2006) First episode psychosis and ethnicity: initial findings from the AESOP study. World Psychiatry, 5, 40-46.

Singh, S. P. (2007) Institutional racism in psychiatry: lessons from inquiries. Psychiatric Bulletin, 31, 363-365.

Rathod, S., Kingdon, D., Smith, P., et al (2005) Insight into schizophrenia: the effects of cognitive behaviorial therapy on the components of insight and association with sociodemographics - data on a previously published randomised controlled trial. Schizophrenia Research, 74, 211-219. 